\title{
Endoscopy and antiplatelet agents. European Society of Gastrointestinal Endoscopy (ESGE) Guideline
}

Authors

Institutions

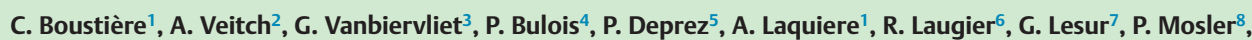
B. Nalet ${ }^{9}$, B. Napoleon ${ }^{10}$, B. Rembacken ${ }^{11}$, N. Ajzenberg ${ }^{12}$, J. P. Collet ${ }^{13}$, T. Baron ${ }^{14}$, J.-M. Dumonceau ${ }^{15}$

Institutions are listed at the end of article. submitted

15 December 2010

accepted after revision

21 December 2010

Bibliography

Dol http://dx.doi.org/

10.1055/s-0030-1256317

Endoscopy 2011; 43:

445-458 ๑ Georg Thieme

Verlag KG Stuttgart · New York

ISSN 0013-726X

Corresponding author

J.-M. Dumonceau, MD, PhD

Service of Gastroenterology and

Hepatology

Geneva University Hospitals

Rue Gabrielle-Perret Gentil 4

1211 Genève 14

Switzerland

Fax: +41-22-3729366

jmdumonceau@hotmail.com
With the increasing use of antiplatelet agents (APA), their management during the periendoscopic period has become a more common and more difficult problem. The increase in use is due to the availability of new drugs and the widespread use of drug-eluting coronary stents. Acute coronary syndromes can occur when APA therapy is withheld for noncardiovascular interventions. Guidelines about APA management during the periendoscopic period are traditionally based on assessments of the procedure-related risk of bleeding and the risk of thrombosis if APA are

\section{Introduction}

$\nabla$

Antiplatelet agents (APA) reduce the aggregation of platelets and are commonly used in patients with coronary heart disease, peripheral arteriopathy, and cardiac arrhythmias. Coronary heart disease represents the most frequent indication because there is a risk of coronary stent occlusion which requires continuous treatment with APA. The risk of stent occlusion is most important in the immediate post-stent placement period. There are varying levels of thrombotic risk depending on the type of stent placed (bare or drug-eluting stent) as well as other risk factors [1]. Conditions that require APA therapy as well as the modalities of APA administration have recently been updated in guidelines issued by the European Society of Cardiology and the European Association for Cardio-Thoracic Surgery [2].

The discontinuation of APA therapy in patients undergoing a noncardiovascular intervention accounts for approximately $5 \%$ of hospitalizations for acute coronary syndrome. Therefore, periendoscopic management of patients with a high thrombotic risk if APA is stopped requires knowledge of both the bleeding risk associated with endoscopic procedures and the potential risks associated with discontinuation of APA therapy [3]. stopped. New data allow better assessment of these risks, of the necessary duration of APA discontinuation before endoscopy, of the use of alternative procedures (mostly for endoscopic retrograde cholangiopancreatography [ERCP]), and of endoscopic methods that can be used to prevent bleeding (following colonic polypectomy). This guideline makes graded, evidence-based, recommendations for the management of APA for all currently performed endoscopic procedures. A short summary and two Tables are included for quick reference.

In this Guideline, the current evidence is reviewed and recommendations made for the management of APA therapy in patients undergoing endoscopic procedures.

\section{Methods}

\section{$\nabla$}

The European Society of Gastrointestinal Endoscopy (ESGE) commissioned and funded this Guideline, which was based on preparatory work performed by the French Society of Digestive Endoscopy. The process was similar to that used in creating other ESGE guidelines [4]. It included face-to-face meetings, teleconferences, and electronic-based discussions among subgroups and members of the entire committee during 2010. Subgroups were formed, each of which was charged with a series of clearly defined key questions (see Appendix e1, available online). The committee chair worked with subgroup leaders to identify pertinent search terms (see Appendix e2, available online). Searches of Medline (via Pubmed), the Cochrane Library, Embase, and the internet were performed. Articles were first selected by title; their relevance was then confirmed by review of the corresponding abstract. Publications with content that was considered irrelevant were excluded. Additional articles were identified 
Table 1 Definitions of categories for evidence levels and recommendation grades used in this Guideline [5].

\begin{tabular}{|c|c|}
\hline \multicolumn{2}{|c|}{ Evidence level } \\
\hline $\begin{array}{l}1+ \\
+\end{array}$ & $\begin{array}{l}\text { High quality meta-analyses, systematic reviews of RCTs, or RCTs } \\
\text { with a very low risk of bias }\end{array}$ \\
\hline $1+$ & $\begin{array}{l}\text { Well conducted meta-analyses, systematic reviews of RCTs, or } \\
\text { RCTs with a low risk of bias }\end{array}$ \\
\hline $1-$ & Meta-analyses, systematic reviews, or RCTs with a high risk of bias \\
\hline $\begin{array}{l}2+ \\
+\end{array}$ & $\begin{array}{l}\text { High quality systematic reviews of case-control or cohort } \\
\text { studies; high quality case-control studies } \\
\text { or cohort studies with a very low risk of confounding, bias, or } \\
\text { chance, and a high probability that the relationship is causal }\end{array}$ \\
\hline $2+$ & $\begin{array}{l}\text { Well conducted case-control or cohort studies with a low risk of } \\
\text { confounding, bias, or chance, and a moderate probability that the } \\
\text { relationship is causal }\end{array}$ \\
\hline 2- & $\begin{array}{l}\text { Case-control or cohort studies with a high risk of confounding, } \\
\text { bias, or chance and a significant risk that the relationship is not } \\
\text { causal }\end{array}$ \\
\hline 3 & Nonanalytic studies, e.g. case reports, case series \\
\hline 4 & Expert opinion \\
\hline \multicolumn{2}{|c|}{ Recommendation grades } \\
\hline A & $\begin{array}{l}\text { At least one meta-analysis, systematic review, or RCT rated as 1++ } \\
\text { and directly applicable to the target population } \\
\text { or a systematic review of RCTs } \\
\text { or a body of evidence consisting principally of studies rated as 1+ } \\
\text { directly applicable to the target population and demonstrating } \\
\text { overall consistency of results }\end{array}$ \\
\hline B & $\begin{array}{l}\text { A body of evidence including studies rated as } 2++ \text { directly applic- } \\
\text { able to the target population and demonstrating overall consis- } \\
\text { tency of results } \\
\text { or extrapolated evidence from studies rated as } 1++ \text { or } 1+\end{array}$ \\
\hline $\mathrm{C}$ & $\begin{array}{l}\text { A body of evidence including studies rated as } 2+\text { directly applic- } \\
\text { able to the target population and demonstrating overall consis- } \\
\text { tency of results } \\
\text { or extrapolated evidence from studies rated as } 2++\end{array}$ \\
\hline $\mathrm{D}$ & $\begin{array}{l}\text { Evidence level } 3 \text { or } 4 \text { or extrapolated evidence from studies rated } \\
\text { as } 2+\end{array}$ \\
\hline
\end{tabular}

$\mathrm{RCT}$, randomized controlled trial.

by manually searching the reference lists of retrieved papers. A central repository of selected literature was made available to all members of the guideline development group. Evidence tables were generated for each key question based on meta-analyses or randomized controlled trials (RCTs) if these were available; otherwise, case-control studies, retrospective analyses, and case series were included. The number of articles retrieved and selected for each task force is indicated in the Evidence table (see Appendix e3, available online).

For important outcomes, articles were individually assessed by using the Method for Evaluating Research and Guideline Evidence (MERGE) checklists as amended by the Scottish Intercollegiate Guidelines Network [5]. Evidence levels and recommendation grades used in these guidelines were those recommended by the amended Scottish Intercollegiate Guidelines Network (- Table 1) [5].

Subgroups agreed electronically on draft proposals that were presented to the entire group for general discussion during a meeting held in 2010 at the 18th United European Gastroenterology Week in Barcelona, Spain. During the meeting and following discussion, competing proposals for wording of recommendations or assigning strength of evidence were resolved by formal voting. When the Guideline development group was unable to reach a unanimous recommendation, the difference of opinion was formally recorded and the reasons for dissent were noted. The results of that discussion were incorporated into the subse- quent Guideline version and again discussed using electronic mail. Literature searches were repeated in October 2010. Studies that were published after this date were not considered for inclusion. This time-point should be the starting point for literature searches when this Guideline is updated.

The manuscript was edited for style by the corresponding author, with approval by subgroup leaders and then by all members of the Guideline development group. In November 2010 the final draft was sent to all individual ESGE members. After incorporation of comments made by the individual ESGE members, the ESGE Governing Board endorsed the manuscript. It was sent to the Editorial Board of the journal Endoscopy. It underwent international peer review and all members of the Guideline development group approved the final version.

Evidence statements and recommendations are stated in italics: key evidence statements and recommendations are in bold. This Guideline was issued in 2011 and will be considered for review in 2014, or sooner if substantially different evidence becomes available. Any updates to the Guideline in the interim period will be noted on the ESGE website: http://www.esge.com/esge-guidelines.html.

\section{Summary of statements and recommendations}

\section{Antiplatelet agents}

Low doses of aspirin and thienopyridines (clopidogrel and prasugrel) irreversibly inhibit platelet aggregation. The minimal durations of APA discontinuation that allow for restoration of normal platelet aggregability are 5 days for aspirin/clopidogrel and 7 days for prasugrel.

APA management during the periendoscopic period balances the estimated risk of bleeding associated with the intended procedure and the risk of a thrombotic event when APA are withheld. The risks of bleeding associated with the most commonly performed endoscopic procedures are discussed in the following paragraphs. A summary of general and specific recommendations for the management of APA therapy during the periendoscopic period is presented in $\square$ Table 2 and $\mathbf{3}$.

\section{Standard diagnostic endoscopy with or without performance of mucosal biopsy}

Esophagogastroduodenoscopy (EGD), colonoscopy, push enteroscopy and endoscopic ultrasonography (EUS) without fine-needle aspiration (FNA) present a minimal bleeding risk (Evidence level 2++). Mucosal biopsy sampling at any digestive site is associated with a very low bleeding risk that is not increased in patients taking APA (aspirin or clopidogrel) (Evidence level 2+). Prasugrel is likely to confer a low bleeding risk similar to that of clopidogrel in diagnostic endoscopic procedures (Evidence level 4).

For the diagnostic endoscopic procedures listed above without biopsy sampling, it is recommended to continue all APA treatment (Recommendation grade $B$ ). If biopsy sampling is indicated in patients taking single APA therapy of aspirin or clopidogrel, we recommend continuing APA therapy (Recommendation grade $C$ ). In patients taking a combination of aspirin and thienopyridines, we recommend continuing dual APA therapy if mucosal biopsies without electrocautery are anticipated (Recommendation grade D). For small-caliber EGD, the transoral rather than the transnasal route should be considered in patients receiving dual APA therapy (Recommendation grade D). 
Table 2 Management of antiplatelet agent therapy during the periendoscopic period.

\begin{tabular}{|c|c|c|}
\hline & Endoscopy with low bleeding risk & Endoscopy with high bleeding risk \\
\hline $\begin{array}{l}\text { Low thrombotic risk* } \\
\text { - Coronary DES }>12 \text { months previously } \\
\text { - Bare metal coronary stents inserted }>6 \text { weeks } \\
\text { previously without associated risk factors } \dagger \\
\text { - Stroke without cardiac failure }>6 \text { weeks previously }\end{array}$ & Maintain APA therapy & $\begin{array}{l}\text { - Stop aspirin } 5 \text { days only for EUS-FNA of cysts, EMR } \\
\text { and ESD, ampullary resection and endoscopic } \\
\text { sphincterotomy with large-balloon papillary dilation } \\
\text { for biliary stone extraction } \\
\text { - In patients taking a thienopyridine alone, it is } \\
\text { recommended to substitute aspirin } \ddagger\end{array}$ \\
\hline $\begin{array}{l}\text { High thrombotic risk* } \\
\text { - Coronary DES inserted } \leq 12 \text { months previously } \\
\text { - Bare metal coronary stents inserted } \leq 6 \text { weeks } \\
\text { previously or }>6 \text { weeks with associated risk factors } \dagger \\
\text { - Stroke } \leq 6 \text { weeks previously }\end{array}$ & Main & $\begin{array}{l}\text { - Delay endoscopy and/or consult cardiologist to } \\
\text { discuss temporary cessation of thienopyridine: } \\
\text { - clopidogrel, } 5 \text { days } \\
\text { - prasugrel, } 7 \text { days } \\
\text { - Aspirin should be maintained in all cases }\end{array}$ \\
\hline \multicolumn{3}{|c|}{$\begin{array}{l}\text { APA, antiplatelet agent; DES, drug-eluting stent; EMR, endoscopic mucosal resection; ESD, endoscopic submucosal dissection; EUS-FNA, endoscopic ultrasonogra- } \\
\text { phy-guided fine needle aspiration; PEG, percutaneous endoscopic gastrostomy. } \\
\text { * Patients with a low thrombotic risk receive a single antiplatelet agent; those with a high thrombotic risk receive two antiplatelet agents. } \\
\dagger \text { Risk factors: diabetes, renal failure, cancer, chronic heart failure, complex coronary artery stenosis, or history of coronary stent thrombosis. } \\
¥ \text { Thienopyridines should be stopped (clopidogrel } 5 \text { days and prasugrel } 7 \text { days) prior to procedure and aspirin substituted. Thienopyridines will be resumed shortly } \\
\text { after the procedure if aspirin is inadequate for long-term prevention. }\end{array}$} \\
\hline
\end{tabular}

\section{Resection of colon polyps}

Post-polypectomy bleeding (PPB) is more frequent with the use of pure-cutting current as compared with blended or coagulation current. (Evidence level 2+). Definite risk factors for PPB include age $>65$ years, anticoagulation, cardiovascular disease, polyp size $\geq 1 \mathrm{~cm}$ (Evidence level 2++). Aspirin does not increase the risk of $P P B$, irrespective of polyp size (Evidence level $2++$ ). In patients taking clopidogrel, resection of small polyps $(\leq 1 \mathrm{~cm})$ followed by endoclip placement (either routinely or in cases of excessive intraprocedural bleeding) has been reported to be relatively safe; in these patients, the use of clopidogrel alone was not an independent predictor of PPB but the concomitant use of clopidogrel and aspirin/ NSAIDs (nonsteroidal anti-inflammatory drugs) was an independent predictor (Evidence level 2+).
Endoscopic interventions that are effective in preventing PPB include placement of a detachable loop ligating device for large pedunculated polyps and submucosal injection of diluted adrenaline for sessile polyps. Efficacy of other measures, including endoclip placement, injection of saline and argon plasma coagulation, has not been definitively demonstrated (Evidence level 1+).

For polypectomy, it is recommended that pure-cutting current is not used (Recommendation grade $C$ ). It is also recommended that aspirin is not discontinued irrespective of polyp size (Recommendation grade $B$ ), and that thienopyridines are withheld if polyps $>1 \mathrm{~cm}$ have to be resected, provided that the patient is not at high risk for thrombotic events (Recommendation grade C). When polyps must be resected in patients who cannot discontinue thienopyridines, preventive measures (preferably detachable loop ligating device for pedunculated polyps, and sub-

\begin{tabular}{|c|c|c|c|}
\hline Bleeding risk & Endoscopic procedure & $\begin{array}{l}\text { Continuation of } \\
\text { aspirin? }\end{array}$ & $\begin{array}{l}\text { Continuation of clopi- } \\
\text { dogrel or prasugrel? }\end{array}$ \\
\hline \multirow[t]{8}{*}{ Low risk } & $\begin{array}{l}\text { EGD and colonoscopy } \\
+/- \text { biopsy }\end{array}$ & Yes & Yes \\
\hline & EUS without FNA & Yes & Yes \\
\hline & Colonic polypectomy $<1 \mathrm{~cm}$ & Yes & No* \\
\hline & Dilation of digestive stenoses & Yes & No \\
\hline & EUS-FNA of solid masses & Yes & No \\
\hline & Digestive stenting & Yes & No \\
\hline & $\begin{array}{l}\text { ERCP with stent placement or papillary } \\
\text { balloon dilation without endoscopic } \\
\text { sphincterotomy }\end{array}$ & Yes & Yes \\
\hline & Argon plasma coagulation & Yes & Not \\
\hline \multirow[t]{7}{*}{ High risk } & EMR, ESD and ampullary resection & No & No \\
\hline & Endoscopic sphincterotomy & Yes & No \\
\hline & $\begin{array}{l}\text { Endoscopic sphincterotomy + large-balloon } \\
\text { papillary dilation }\end{array}$ & No & No \\
\hline & Colonic polypectomy $>1 \mathrm{~cm}$ & Yes & $\mathrm{No}^{*}$ \\
\hline & EUS-FNA of cystic lesions & No & No \\
\hline & Percutaneous endoscopic gastrostomy & Yes & n. a. \\
\hline & Esophageal variceal band ligation & Yes & No \\
\hline \multicolumn{4}{|c|}{$\begin{array}{l}\text { EGD, esophagogastroduodenoscopy; ERCP, endoscopic retrograde cholangiopancreatography; EMR, endoscopic mucosal re- } \\
\text { section; ESD, endoscopic submucosal dissection; EUS, endoscopic ultrasonography; EUS-FNA, endoscopic ultrasonography- } \\
\text { guided fine-needle aspiration; } n \text {. a., not available. } \\
\text { * Bleeding may be prevented by placing a detachable loop ligating device or, if not possible, by submucosal injection of diluted } \\
\text { adrenaline. The resection of small polyps }(<1 \mathrm{~cm} \text { ) is probably safe in patients taking clopidogrel (not prasugrel) with such } \\
\text { preventive measures; insufficient data are available concerning prophylactic endoclip placement. }\end{array}$} \\
\hline
\end{tabular}

Table 3 Endoscopic procedures and risk of bleeding. 
mucosal injection of diluted adrenaline for sessile polyps) should be readily available (Recommendation grade B). In patients with large polyps who are receiving thienopyridines, biopsy sampling with deferral of polypectomy should be considered (Recommendation grade $D$ ).

\section{Endoscopic mucosal resection and submucosal dissection}

The risk of bleeding doubles when lesions are removed by endoscopic submucosal dissection (ESD) compared with endoscopic mucosal resection (EMR) (Evidence level 1+). Both techniques have always been performed after withholding APA; a short washout period has been associated with more post-procedure bleeding after gastric ESD (Evidence level 2-). For EMR and ESD, discontinuation of all APA, including aspirin, is recommended provided the patient is not at high risk for a thrombotic event (Recommendation grade C).

\section{Endoscopic biliary and pancreatic sphincterotomy}

The risk of post-endoscopic sphincterotomy hemorrhage (PESH) is not increased with aspirin use (Evidence level 2+). The risk of PESH has not been sufficiently assessed when clopidogrel or prasugrel were continued. PESH is significantly less frequent when blended rather than pure-cutting current is used during endoscopic sphincterotomy. Large-balloon papillary dilation after endoscopic sphincterotomy for extraction of difficult biliary stones has been associated with frequent intraprocedural oozing and, less frequently, severe bleeding (Evidence level 2+); no data have been reported with this technique in patients taking APA.

Alternatives to endoscopic sphincterotomy that eliminate the risk of bleeding include endoscopic papillary balloon dilation (EPBD) using small-caliber ( $\leq 10 \mathrm{~mm}$ ) balloons and, for obstructing biliary stones, temporary stent placement without endoscopic sphincterotomy. The respective drawbacks of each of these alternatives include an increased risk of post-endoscopic retrograde cholangiopancreatography pancreatitis (PEP) and a high morbidity/mortality in the case of long-term biliary stent placement (Evidence level $1+$ ).

For endoscopic sphincterotomy, it is recommended: (i) to continue aspirin (Recommendation grade $\mathrm{C}$ ), (ii) to withhold clopidogrel or prasugrel (Recommendation grade $D$ ), and (iii) to use blended current (Recommendation grade $A$ ). For the extraction of large biliary stones in patients taking aspirin, mechanical lithotripsy is recommended over endoscopic sphincterotomy plus large-balloon dilation (the latter technique should be performed after withholding any APA) (Recommendation grade D). If APA discontinuation is considered too risky, EPBD using small-caliber balloons or temporary biliary stent placement should be considered as an alternative. If EPBD is performed in young patients, the placement of a prophylactic pancreatic stent should be considered (if the endoscopist is not proficient in this technique, biliary stent placement is recommended rather than EPBD). After biliary stent placement, the patient and referring physicians should be warned that when used as a long-term measure, stent placement is associated with a high risk of cholangitis (Recommendation grade $B$ ).

Endoscopic ultrasound-guided fine-needle aspiration Based on limited data, aspirin does not increase the hemorrhagic risk of endoscopic ultrasound-guided fine-needle aspiration (EUSFNA) (Evidence level 2+); no data were found for thienopyridines. In the case of pancreatic cystic lesions, EUS-FNA could carry a higher incidence of bleeding compared with other lesions but data are conflicting. After EUS-guided brushing of pancreatic cysts, severe delayed bleeding has been reported in patients receiving anticoagulant therapy, even when withheld before the procedure (Evidence level 2-).

It is recommended that thienopyridines are discontinued before any EUS-FNA and that aspirin be withheld before EUSFNA of pancreatic cysts in patients with a low risk of thrombotic events. EUS-guided brushing of pancreatic cysts is not advised in patients receiving any APA, even if these are temporarily discontinued (Recommendation grade D). For other EUSFNAs, aspirin should not be discontinued (Recommendation grade $C$ ).

\section{Endoscopic stent placement and dilation of} gastrointestinal strictures

No studies have specifically evaluated the bleeding risk associated with endoscopic dilation or stent placement in patients taking APA but the overall bleeding risk associated with these procedures is very low (Evidence level 2+).

For endoscopic dilation of digestive strictures or stent placement, we recommend not to discontinue aspirin (except when large-diameter pneumatic achalasia balloon dilation is performed), but to discontinue clopidogrel or prasugrel (Recommendation grade D).

Percutaneous endoscopic gastrostomy (PEG) placement There are limited data on the bleeding risk associated with percutaneous endoscopic gastrostomy (PEG) placement in patients taking APA: three recent studies have shown that aspirin does not increase the bleeding risk (Evidence level $2+$ ). We recommend continuing aspirin in patients undergoing PEG placement (Recommendation grade $C$ ). In the absence of appropriate studies, no recommendation can be made for patients taking clopidogrel or a combination of aspirin and thienopyridines.

\section{Device-assisted enteroscopy}

The bleeding risk of device-assisted enteroscopy (using either single- or double-balloon or spiral techniques) in patients taking APA has not been formally evaluated. We recommend continuing aspirin and considering discontinuation of thienopyridines (Evidence grade $D$ ).

\section{Esophageal variceal ligation (EVL)}

In the only published small-sized study of prophylactic EVL, the risk of bleeding was similar in patients taking aspirin or not (Evidence level 2-). It is recommended that for EVL aspirin is continued (Recommendation grade C) and thienopyridines are withheld (Recommendation grade $D$ ).

\section{Hemostatic treatment using argon plasma coagulation (APC)}

There are limited data on the use of argon plasma coagulation (APC) in patients taking aspirin and other APA. In one study, aspirin and clopidogrel were not identified as risk factors for delayed bleeding after APC of mucosal vascular lesions (Evidence level 2+). It is recommended that aspirin or clopidogrel is continued in patients undergoing APC of potentially bleeding lesions (Recommendation grade $C$ ). In the absence of appropriate studies, no recommendation can be made for patients taking a combination of aspirin and thienopyridines. 


\section{Antiplatelet agents}

$\nabla$

\subsection{Pharmacology and clinical use}

Low doses of aspirin and thienopyridines (clopidogrel and prasugrel) irreversibly inhibit platelet aggregation. The minimal durations of APA discontinuation that allow for restoration of normal platelet aggregability are 5 days for aspirin/clopidogrel and 7 days for prasugrel.

APA management during the periendoscopic period balances the estimated risk of bleeding associated with the intended procedure and the risk of a thrombotic event when APA are withheld. The risks of bleeding associated with the most commonly performed endoscopic procedures are discussed in the following paragraphs. A summary of general and specific recommendations for the management of APA therapy during the periendoscopic period is presented in $\odot$ Table 2 and 3.

Aspirin and thienopyridines (clopidogrel and prasugrel) are the most commonly used APA [6,7]; they have different mechanisms of action on platelets and are often used in combination:

- Aspirin commonly used at low dosage (75 to $160 \mathrm{mg}$ daily) decreases platelet aggregation by irreversibly inhibiting cyclooxygenase-1, thus blocking the synthesis of thromboxane A2, a potent platelet-activating agent. Although the half-life of aspirin is short, its effect lasts for the lifespan of the platelets.

- Clopidogrel is an inactive pro-drug; following intestinal absorption, it is extensively transformed into an inactive metabolite that requires cytochrome P450-dependent metabolic activation. The active metabolite irreversibly binds to an adenosine diphosphate platelet receptor and, hence, irreversibly inhibits platelet aggregation.

- Prasugrel has the same pharmacologic action as clopidogrel but with more consistent levels of platelet inhibition with less susceptibility to genetic variation and drug-drug interactions [8].

The efficacy of aspirin and clopidogrel largely varies between individuals, depending on the state of platelet activation and genetic factors. No routine hemostatic tests can reliably assess the level of platelet activity in patients taking APA and help to assess the hemorrhagic risk. Platelet counts and coagulation tests are only useful in these patients to search for other potential causes of increased bleeding risks, particularly in the case of bleeding history.

In the near future, ticagrelor, a novel APA chemically distinct from thienopyridines that reversibly inhibits platelets, might simplify the perioperative and periendoscopic management of patients taking APA [9]. Pharmacological studies have shown that prasugrel and ticagrelor have a more potent and reliable antiplatelet effect than clopidogrel and these drugs may therefore present a higher hemorrhagic risk.

In many cases, oral anticoagulants or heparin cannot be used as a substitute for APA. For example, heparin (unfractionated or lowmolecular-weight heparin) is not recommended for the prevention of coronary stent thrombosis.

\subsection{Discontinuation of antiplatelet agents}

As $10 \%$ of platelets renew each day and a concentration of 50000 new platelets per microliter of blood confers normal clotting, it can be calculated that the minimal durations of APA discontinuation that allow for restoration of normal platelet aggregability are 5 days for aspirin/clopidogrel and 7 days for prasugrel (based on the prolonged and more effective action of prasugrel compared with clopidogrel) [8].
Patients who require two APA due to high thrombotic risk should never discontinue aspirin and any consideration regarding the withholding of thienopyridines should first be discussed with a cardiologist. For patients taking clopidogrel alone, aspirin can be substituted during the periendoscopic period for high-risk bleeding procedures. To date, no published data are available concerning the bleeding risk associated with the use of ticagrelor. APA treatment should be resumed no later than 24-48 hours after the procedure but may be delayed on a case-by-case basis to prevent severe bleeding complications [7]. A summary of recommendations is seen in $\bullet$ Table $\mathbf{2}$ and $\mathbf{3}$.

\section{Endoscopic procedures}

\section{$\nabla$}

\subsection{Standard diagnostic endoscopy with or without mucosal biopsy}

Esophagogastroduodenoscopy (EGD), colonoscopy, push enteroscopy and endoscopic ultrasonography (EUS) without fine-needle aspiration (FNA) present a minimal bleeding risk (Evidence level 2++). Mucosal biopsy sampling at any digestive site is associated with a very low bleeding risk that is not increased in patients taking APA (aspirin or clopidogrel) (Evidence level 2+). Prasugrel is likely to confer a low bleeding risk similar to that of clopidogrel in diagnostic endoscopic procedures (Evidence level 4).

For the diagnostic endoscopic procedures listed above without biopsy sampling, it is recommended to continue all APA treatment (Recommendation grade $B$ ). If biopsy sampling is indicated in patients taking single APA therapy of aspirin or clopidogrel, we recommend continuing APA therapy (Recommendation grade C). In patients taking a combination of aspirin and thienopyridines, we recommend continuing dual APA therapy if mucosal biopsies without electrocautery are anticipated (Recommendation grade $D$ ). For small-caliber EGD, the transoral rather than the transnasal route should be considered in patients receiving dual APA therapy (Recommendation grade $D$ ).

The risk of bleeding associated with diagnostic endoscopy has been assessed in several large studies that included in total thousands of patients [10 - 13]. These studies have shown that bleeding is very rare after diagnostic endoscopic procedures, including those with mucosal biopsy sampling. No episodes of severe bleeding have been reported. Transnasal esophagogastroduodenoscopy (EGD) may be associated with an increased risk of epistaxis, depending on the diameter of the endoscope $[14,15]$. However, these studies were not designed to examine bleeding risks in patients taking aspirin or thienopyridines.

Four studies have specifically evaluated the bleeding risk of diagnostic endoscopy with biopsy sampling in patients taking APA [16-19]. In a nonrandomized study of 180 patients, colonic mucosal bleeding time was significantly increased in patients taking APA but without clinical consequences [16]. Another study showed that aspirin did not prolong gastric bleeding time [17]. A retrospective study of 133 patients (including 16 patients taking NSAIDs), in whom multiple (9661) biopsy samples were obtained during 253 endoscopies, found that minor complications occurred in only 13 (5.1\%) patients, including 8 episodes of selflimited bleeding [19]. Multivariate analysis showed no increased bleeding risk in patients with recent NSAID use. Neither the type of endoscopic procedure nor the site of biopsy was associated with bleeding.

Two previous national guidelines on APA management for endoscopic procedures recommended continuing aspirin and/or clo- 
Table 4 Risk factors* for hemorrhagic adverse events following colonic polypectomy.

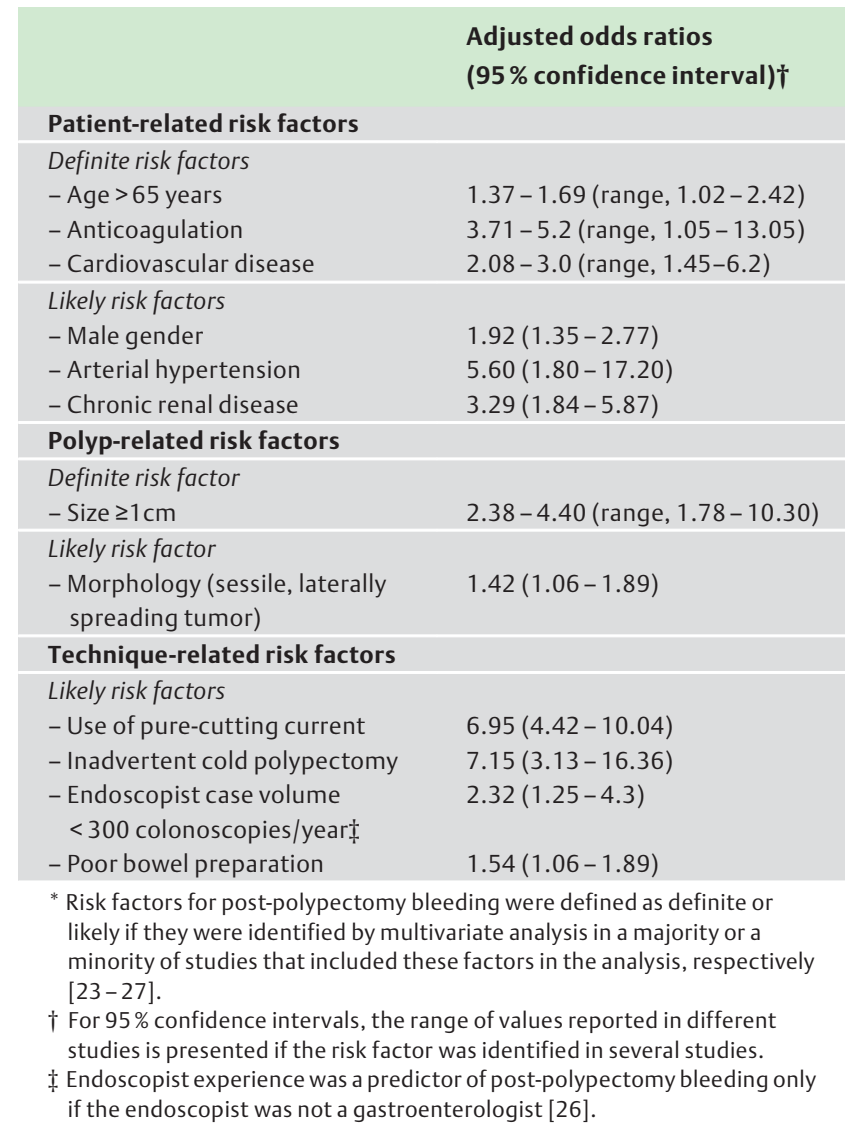

pidogrel when performing endoscopic procedures with low bleeding risk $[20,21]$. These conclusions were validated by a recent prospective, single-blind, randomized study that analyzed the risk of bleeding after biopsy sampling during EGD in 45 healthy volunteers taking either aspirin (280 biopsy samples) or clopidogrel (350 biopsy samples) [18]. Only one patient experienced endoscopic bleeding from the gastric antrum while continuing aspirin. This was without clinical significance and was treated immediately by submucosal injection of diluted adrenaline. There are no data regarding the risk of bleeding associated with endoscopic biopsy sampling while continuing prasugrel, but it is likely to be similar to that of clopidogrel.

\subsection{Resection of colonic polyps}

Post-polypectomy bleeding (PPB) is more frequent with the use of pure-cutting current as compared with blended or coagulation current. (Evidence level 2+). Definite risk factors for PPB include age $>65$ years, anticoagulation, cardiovascular disease, polyp size $\geq 1 \mathrm{~cm}$ (Evidence level 2++). Aspirin does not increase the risk of $P P B$, irrespective of polyp size (Evidence level $2++$ ). In patients taking clopidogrel, resection of small polyps $(\leq 1 \mathrm{~cm})$ followed by endoclip placement (either routinely or in cases of excessive intraprocedural bleeding) has been reported to be relatively safe; in these patients, the use of clopidogrel alone was not an independent predictor of PРB but the concomitant use of clopidogrel and aspirin/ NSAID (nonsteroidal anti-inflammatory drugs) was an independent predictor (Evidence level 2+).

Endoscopic interventions that are effective in preventing PPB include placement of a detachable loop ligating device for large pedunculated polyps and submucosal injection of diluted adrenaline for sessile polyps. Efficacy of other measures, including endoclip placement, injection of saline and argon plasma coagulation, has not been definitively demonstrated (Evidence level 1+).

For polypectomy, it is recommended that pure-cutting current is not used (Recommendation grade $C$ ). It is also recommended that aspirin is not discontinued irrespective of polyp size (Recommendation grade $B$ ), and that thienopyridines are withheld if polyps $>1 \mathrm{~cm}$ have to be resected, provided that the patient is not at high risk for thrombotic events (Recommendation grade C). When polyps must be resected in patients who cannot discontinue thienopyridines, preventive measures (preferably detachable loop ligating device for pedunculated polyps, and submucosal injection of diluted adrenaline for sessile polyps) should be readily available (Recommendation grade B). In patients with large polyps who are receiving thienopyridines, biopsy sampling with deferral of polypectomy should be considered (Recommendation grade $D$ ).

Only two high-quality studies were identified in which the incidence of post-polypectomy bleeding (PPB) could be calculated: these studies were recent, large, and prospective with a minimum follow-up of 14 days after polypectomy [22,23]. The overall incidence of PPB was 2.9\% (199/6849 patients) and the incidence of severe PPB (defined as requiring blood transfusion, hospitalization, surgery, or resulting in death) was $1.1 \%$ (43/3929 patients) [22].

Definite and likely risk factors for PPB are summarized in $\bullet$ Table 4. Among polyp-related factors, a large polyp size is the most consistent risk factor. It has been calculated that for every $1-\mathrm{mm}$ increase in polyp diameter, the risk of PPB increases by $9 \%$ [23]. Good clinical practices for the resection of large polyps include the use of endoscopic interventions that have been demonstrated to effectively prevent PPB $(\bullet$ Table 5$)$. Furthermore, referral to specialized centers should be considered. In a study of $174 \mathrm{pa}-$ tients referred for resection of large or complex polyps (median diameter, $30 \mathrm{~mm}$ ), delayed PPB occurred in $3.7 \%$ of patients [35]. For colonic snare polypectomy, the use of pure-cutting current is not recommended because it increases the incidence of immediate PPB compared with blended or coagulation currents $[24,36]$. Blended and coagulation currents are associated with similar incidences of PPB, but PPB tends to develop later (up to 8 days) after polypectomy with coagulation compared with blended current [37].

The influence of aspirin use on PPB has been analyzed in casecontrol studies including a total of 30000 patients ( Table $\mathbf{6}$ ). These studies varied in many aspects, including design, definition of PPB, technique of polypectomy, methods used for selecting controls with no PPB, and discrimination of aspirin from other NSAIDs. Despite these differences, all studies found that the risk of significant PPB was not increased by aspirin use.

The influence of clopidogrel intake on PPB has been analyzed in two retrospective studies including 202 patients taking clopidogrel (associated with aspirin/NSAID use in 27\%) undergoing 500 polypectomies (polyp size $\leq 10 \mathrm{~mm}$ in $93 \%$ of cases) [41,42]. In $6 \%$ of patients, the polypectomy was associated with immediate bleeding which was successfully treated by endoclip placement. Delayed PPB developed in 3\% of patients. Of note, endoclips were placed after all polypectomies in one of the two studies and in only $4.2 \%$ of patients in the second study. Bleeding developed up to 14 days after polypectomy. In one study there was a control group (1243 patients undergoing polypectomy in the absence of clopidogrel) which allowed identification of independent risk factors for PPB [41]. Risk factors included the concomitant use of clopidogrel and aspirin/NSAID but not the use of clo- 
Table 5 Randomized controlled trials of endoscopic interventions to prevent bleeding after snare resection of large colon polyps in patients taking no antiplatelet agent.

\begin{tabular}{|c|c|c|c|c|c|}
\hline First author, year & Patients, n & Methods compared & Polyp size, mm & $\begin{array}{l}\text { Bleeding incidence } \\
\text { (immediate + delayed) }\end{array}$ & P value \\
\hline Dobrowolski, 2004 [28] & 69 & Adrenaline vs. no intervention & $>10$ & $2 \%$ vs. $16 \%$ & $<0.05$ \\
\hline Lee, 2007 [29] & 486 & Adrenaline vs. saline injection & $>20$ & $4.9 \%$ vs. $10.4 \%$ & $0.03^{*}$ \\
\hline lishi, 1996 [30] & 89 & $\begin{array}{l}\text { Detachable loop ligating device vs. } \\
\text { no intervention }\end{array}$ & $>10$ & 0 vs. $12 \%$ & $0.02^{*}$ \\
\hline Di Giorgio, 2004 [31] & 488 & $\begin{array}{l}\text { Detachable loop ligating device vs. } \\
\text { adrenaline vs. no intervention }\end{array}$ & 22.1 vs. 24.7 vs. 21.5 & $1.8 \%$ vs. $3.1 \%$ vs. $7.9 \%$ & n. s. $\dagger$ \\
\hline Kouklakis, 2009 [32] & 64 & $\begin{array}{l}\text { Adrenaline vs. detachable loop li- } \\
\text { gating device + clip }\end{array}$ & $>20$ & $12.5 \%$ vs. $3.1 \%$ & 0.02 \\
\hline Paspatis, 2006 [33] & 159 & $\begin{array}{l}\text { Adrenaline vs. adrenaline + detach- } \\
\text { able loop ligating device }\end{array}$ & $>20$ & $10.6 \%$ vs. $2.3 \%$ & 0.02 \\
\hline Lee, 2009 [34] & 475 & $\begin{array}{l}\text { Argon plasma coagulation vs. no } \\
\text { intervention }\end{array}$ & 9.8 vs. 9.5 & $2.5 \%$ vs. $4.3 \%$ & n.s. \\
\hline
\end{tabular}

Table 6 Case-control studies evaluating the risk of hemorrhagic adverse events following colonic polypectomy relative to aspirin intake.

\begin{tabular}{|c|c|c|c|c|c|c|}
\hline \multirow[t]{2}{*}{ First author, year } & \multirow[t]{2}{*}{$\begin{array}{l}\text { Study design } \\
\text { Number of patients }\end{array}$} & \multicolumn{2}{|c|}{$\begin{array}{l}\text { Incidence of PPB in the } \\
\text { whole study population }\end{array}$} & \multicolumn{2}{|c|}{$\begin{array}{l}\text { Patients taking aspirin } \\
\% \\
(\mathrm{n} / \mathrm{n})\end{array}$} & \multirow[t]{2}{*}{$P$ value } \\
\hline & & Type of PPB & Incidence & Cases (PPB) & Controls (no PPB) & \\
\hline \multirow[t]{2}{*}{ Shiffman, 1994 [38] } & $\begin{array}{l}\text { Prospective } \\
464\end{array}$ & Any & $6.5 \%$ & $\begin{array}{l}73 \% \\
(22 / 30)\end{array}$ & $\begin{array}{l}47 \% \\
(206 / 434)\end{array}$ & 0.009 \\
\hline & & Major* & $0.9 \%$ & $\begin{array}{l}100 \% \\
(2 / 2)\end{array}$ & $\begin{array}{l}0 \% \\
(0 / 2)\end{array}$ & 0.73 \\
\hline Yousfi, 2004 [39] & $\begin{array}{l}\text { Retrospective } \\
20636\end{array}$ & Any & $0.5 \%$ & $\begin{array}{l}40 \% \\
(32 / 81)\end{array}$ & $\begin{array}{l}33 \% \\
(27 / 81) \dagger\end{array}$ & 0.36 \\
\hline Hui, 2004 [40] & $\begin{array}{l}\text { Retrospective } \\
1657\end{array}$ & Any & $2.2 \%$ & $\begin{array}{l}14 \% \\
(5 / 37)\end{array}$ & $\begin{array}{l}8 \% \\
(122 / 1620)\end{array}$ & 0.62 \\
\hline \multirow[t]{2}{*}{ Heldwein, 2005 [22] } & $\begin{array}{l}\text { Prospective } \\
2257\end{array}$ & Any & $8.6 \%$ & n.d. & n.d. & n.s. \\
\hline & & Major* & $1.6 \%$ & n.d. & n.d. & n.s. \\
\hline Sawhney, 2008 [23] & $\begin{array}{l}\text { Retrospective } \\
4592\end{array}$ & Delayed & $0.9 \%$ & $\begin{array}{l}41 \% \\
(17 / 41)\end{array}$ & $\begin{array}{l}39 \% \\
(51 / 132) \dagger\end{array}$ & 0.80 \\
\hline
\end{tabular}

n. d., no data; n. s., not significant; PPB, post-polypectomy bleeding.

* Defined as blood loss either warranting emergency consultation [38], or leading to shock, blood transfusion, hospitalization, or surgery, or recurrent bleeding after endoscopic hemostasis [22].

† Controls were selected among study patients who did not develop PPB, either randomly [23], or after matching for age, gender, and cardiovascular morbidity [39].

pidogrel alone as well as the number of polyps resected. Because polyps are found at screening colonoscopy in one-third of average-risk patients, the authors concluded that it is unnecessary to stop clopidogrel therapy for screening colonoscopy in averagerisk patients provided that endoclips are readily available.

Various endoscopic interventions have been used to prevent delayed PPB in patients not taking APA ( $\bullet$ Table 5$)$. Hence, the recommendations presented here for PPB prophylaxis are based on evidence extrapolated from these studies. Submucosal injection of diluted adrenaline was found to be more effective than saline or no intervention in the three RCTs that compared these modalities (in one RCT, the difference was statistically significant only for patients with polyps $\geq 2 \mathrm{~cm}$ ) [31]. In the case of large pedunculated polyps, the placement of a detachable loop ligating device and injection of adrenaline were similarly effective in only one of three RCTs [31]. The disadvantage of detachable loop ligating devices is that their placement requires more expertise than submucosal injection and may not be feasible for very large polyps. In such difficult cases, the endoclip-assisted technique, consisting of clip placement on the polyp pedicle followed by polypectomy using a snare or a needle-knife, has been shown to be as safe and effective as detachable loop ligation device-assisted polypectomy in a small case-control study [43]. There is no evidence that argon plasma coagulation is effective in reducing the risk of PPB [34]. An RCT of prophylactic endoclip placement versus no treatment was not included in our review as patients with large polyps were excluded, resulting in insufficient statistical power to demonstrate efficacy of a prophylactic intervention [44]. A retrospective study that included 123 patients receiving anticoagulants reported an acceptable PPB rate (2.5\%) after resection of 225 polyps (mean and maximum sizes, 5 and $15 \mathrm{~mm}$, respectively) followed in all cases by prophylactic endoclip placement [45].

\subsection{Endoscopic mucosal resection (EMR) and submucosal dissection (ESD)}

The risk of bleeding doubles when lesions are removed by endoscopic submucosal dissection (ESD) compared with endoscopic mucosal resection (EMR) (Evidence level 1+). Both techniques have 
always been performed after withholding APA; a short washout period has been associated with more post-procedure bleeding after gastric ESD (Evidence level 2-). For EMR and ESD, discontinuation of all APA, including aspirin, is recommended provided the patient is not at high risk for a thrombotic event (Recommendation grade C).

Studies reported in this section relate to more recent EMR techniques than the "lift and cut" technique used in some of the studies cited for colonic polypectomy [46]. The "lift and cut" technique is most often used for large colonic polyps to safely perform snare resection; less frequently this technique or more advanced EMR techniques are used for superficial lesions in the upper digestive tract (for gastric lesions, ESD is more frequently used to achieve complete en bloc resection). Endoscopist experience with EMR and ESD is more limited in Western compared with Eastern countries, with a case volume of 7-15 EMRs/year in a recent French survey of endoscopists practicing this technique [47]. In this survey, bleeding was reported after 55 EMRs performed mostly in the colorectum in 1202 patients (bleeding rate, $4.6 \%$ ). In three-quarters of the cases, bleeding developed within 12 hours of EMR. The number of cases with intraprocedural bleeding was not reported. In a German study of esophageal EMR performed by highly experienced endoscopists, bleeding was reported in $42 / 349$ patients (bleeding rate, $12.0 \%$ ), and was graded as severe in $0.6 \%$ of patients [48]. Delayed bleeding following nonampullary duodenal polypectomies has been reported in $3.1 \%$ to $11.6 \%$ of patients included in the five most recent prospective studies (total of 157 polyps) using EMR [49-53]. Ampullary resection is somewhat similar to EMR and presents a significant risk of bleeding (5.6\% of patients in five large retrospective series) [54-58]. Compared with EMR, ESD carries a twofold risk of bleeding (odds ratio, 2.20; 95\% confidence interval, 1.58-3.07) [59]. Hemostatic forceps have been shown to prevent delayed bleeding in a large series of ESD that compared patients treated by means of this device with historical controls. Unfortunately hemostatic forceps are costly [60].

APA were routinely withheld prior to performing EMR and ESD in all large studies. In a multivariate analysis of factors associated with bleeding following gastric ESD, use of "drugs potentially related to gastric injury/bleeding“ (i.e., APA, NSAIDs, anticoagulants, and corticosteroids) were associated with an increased risk of post-ESD bleeding [61]. Aspirin was withheld 3 days before ESD and resumed immediately after. In contrast, other studies have reported no association between post-ESD bleeding and regular aspirin use, but aspirin was discontinued 1 week before the ESD in these studies [62-65].

\subsection{Endoscopic biliary and pancreatic sphincterotomy} The risk of post-endoscopic sphincterotomy hemorrhage (PESH) is not increased with aspirin use (Evidence level 2+). The risk of PESH has not been sufficiently assessed when clopidogrel or prasugrel were continued. PESH is significantly less frequent when blended rather than pure-cutting current is used during endoscopic sphincterotomy. Large-balloon papillary dilation after endoscopic sphincterotomy for extraction of difficult biliary stones has been associated with frequent intraprocedural oozing and, less frequently, severe bleeding (Evidence level 2+); no data have been reported with this technique in patients taking APA.

Alternatives to endoscopic sphincterotomy that eliminate the risk of bleeding include endoscopic papillary balloon dilation (EPBD) using small-caliber $(\leq 10 \mathrm{~mm})$ balloons and, for obstructing biliary stones, temporary stent placement without endoscopic sphincter- otomy. The respective drawbacks of each of these alternatives include an increased risk of PEP and a high morbidity/mortality in the case of long-term biliary stent placement (Evidence level 1+).

For endoscopic sphincterotomy, it is recommended: (i) to continue aspirin (Recommendation grade C), (ii) to withhold clopidogrel or prasugrel (Recommendation grade $D$ ), and (iii) to use blended current (Recommendation grade A). For the extraction of large biliary stones in patients taking aspirin, mechanical lithotripsy is recommended over endoscopic sphincterotomy plus large-balloon dilation (the latter technique should be performed after withholding any APA) (Recommendation grade $D$ ).

If APA discontinuation is considered too risky, EPBD using small-caliber balloons or temporary biliary stent placement should be considered as an alternative. If EPBD is performed in young patients, the placement of a prophylactic pancreatic stent should be considered (if the endoscopist is not proficient in this technique, biliary stent placement is recommended rather than EPBD). After biliary stent placement, the patient and referring physicians should be warned that when used as a long-term measure, stent placement is associated with a high risk of cholangitis (Recommendation grade $B$ ).

Clinically significant PESH complicates $2 \%$ of endoscopic sphincterotomies [66]. Recognized risk factors for PESH include cholangitis, coagulation disorders, institution of anticoagulation within 3 days of endoscopic sphincterotomy, low endoscopist case volume of endoscopic sphincterotomies, and bleeding observed during the procedure [67]. For endoscopic sphincterotomy, blended current is recommended as it reduces the incidence of PESH compared with pure-cutting current without significantly increasing the risk of PEP $[36,68]$.

Three studies that assessed PESH in patients taking APA were identified. In the only prospective study [66], PESH occurred in $2 \%$ of patients, regardless of the use of aspirin or NSAIDs in the 3 days preceding the procedure (PESH and APA, 6/298 vs. PESH and no APA, 42/2299; $P=0.99$ ). In a retrospective case-control study, similar proportions of patients taking APA were found among 40 patients with PESH compared with 86 controls without PESH (13\% aspirin and $3 \%$ clopidogrel vs. $17 \%$ aspirin and $4 \%$ NSAIDs in cases vs. controls, respectively) [69]. In another retrospective case-control study [70], PESH occurred slightly less frequently in 564 controls who had not taken aspirin compared with 240 patients taking aspirin (regardless of whether they had continued or stopped aspirin 1 week prior to endoscopic sphincterotomy). In that study, PESH was more strongly associated with co-morbid illness than with aspirin therapy $(P<0.001$ and $P=0.04$, respectively). No adequately powered study was identified that assessed the risk of PESH in patients taking thienopyridines.

For the removal of large or difficult common bile duct stones, a technique that consists of endoscopic sphincterotomy followed by dilation using large-diameter $(12-20 \mathrm{~mm})$ balloons is increasingly used with high successful stone clearance rates [7174]. However, no data are available for this technique in patients taking APA. In a retrospective series, intraprocedural oozing and clinically significant bleeding were frequently observed (32\% and $7 \%$, respectively) [75]. Moreover, the only RCT that compared endoscopic sphincterotomy alone with endoscopic sphincterotomy combined with large-balloon dilation found no differences in rates of successful stone clearance, need for mechanical lithotripsy, or complications [76].

Compared with endoscopic sphincterotomy, EPBD is an alternative that eliminates the risk of significant hemorrhage, but is less effective for the removal of large biliary stones and carries a high- 
er risk of PEP [77, 78]. Concerns were raised about the risk of severe, life-threatening, PEP in young patients after EPBD, based upon the results of a multicenter US RCT. This trial showed higher rates of severe morbidity following EPBD compared with endoscopic sphincterotomy $(P=0.004)$, including severe PEP $(P=0.01)$ [79]. However, this trial was performed before the use of pancreatic stents for prophylaxis of PEP. Therefore, placement of a prophylactic pancreatic stent should be considered in patients undergoing EPBD, if the endoscopist is proficient in this technique $[80,81]$.

Insertion of a nasobiliary drain or biliary stent without endoscopic sphincterotomy is another therapeutic option to avoid endoscopic sphincterotomy-associated bleeding. Biliary endoscopic sphincterotomy is not necessary for inserting single plastic or metal biliary stents [82]. Stent insertion allows biliary drainage in cases of acute suppurative cholangitis [83]. It has also been reported to partially or completely dissolve biliary stones in $>50 \%$ of cases, facilitating subsequent extraction [84-87]. It should be considered as a bridge towards more definite therapy, as complications (including death in up to $6.7-16 \%$ of cases) of long-term stent placement in this setting are frequent during long followup $[84,88]$.

\subsection{Endoscopic ultrasound-guided fine-needle aspiration}

Based on limited data, aspirin does not increase the hemorrhagic risk of endoscopic ultrasound-guided fine-needle aspiration (EUSFNA) (Evidence level 2+); no data were found for thienopyridines. In the case of pancreatic cystic lesions, EUS-FNA could carry a higher incidence of bleeding compared with other lesions but data are conflicting. After EUS-guided brushing of pancreatic cysts, severe delayed bleeding has been reported in patients receiving anticoagulant therapy, even when withheld before the procedure (Evidence level 2-).

It is recommended that thienopyridines are discontinued before any EUS-FNA and that aspirin be withheld before EUS-FNA of pancreatic cysts in patients with a low risk of thrombotic events. EUSguided brushing of pancreatic cysts is not advised in patients receiving any APA, even if these are temporarily discontinued (Recommendation grade D). For other EUS-FNAs, aspirin should not be discontinued (Recommendation grade $\mathrm{C}$ ).

Prospective studies have shown that bleeding following EUS-FNA is rare and occurs in $<1 \%$ of unselected patients [89-94]. One prospective study assessed the risk of bleeding complicating EUS-FNA in patients taking aspirin/NSAIDs [95]. In this study, 241 lesions were sampled, including solid tumors, cysts and ascites with a mean of approximately 2.5 passes using a $19 \mathrm{G}$ or $22 \mathrm{G}$ needle. There was no significant difference in bleeding between those taking aspirin/NSAIDs ( 0 of 26 patients) compared with controls ( 7 of 190 patients). No difference was detected between groups in terms of cellular yield. There are no studies identified that assessed bleeding after EUS-FNA in patients taking thienopyridines.

The risk of bleeding may be greater when EUS-FNA is performed for pancreatic cystic lesions. In two prospective cohort studies bleeding occurred in $5.5 \%$ of 72 patients, and one of the patients required surgery $[94,96]$. However, in a prospective multicenter cohort study that included 341 patients no bleeding occurred [97]. In four prospective studies of EUS-guided brushing of pancreatic cysts, severe bleeding occurred in $1.5 \%$ of 130 patients, including one that was fatal [98-101]. Bleeding was delayed (7-16 days post-procedurally) and occurred in patients who had anticoagulant therapy discontinued at the time of brushing.

\subsection{Endoscopic stent placement and dilation of gastrointestinal strictures}

No studies have specifically evaluated the bleeding risk associated with endoscopic dilation or stent placement in patients taking APA but the overall bleeding risk associated with these procedures is very low (Evidence level 2+).

For endoscopic dilation of digestive strictures or stent placement, we recommend not to discontinue aspirin (except when large-diameter pneumatic achalasia balloon dilation is performed), but to discontinue clopidogrel or prasugrel (Recommendation grade D). No studies could be identified that have specifically assessed the bleeding risk in patients on APA who have undergone dilation or stent insertion in the esophagus, small bowel and colon. The bleeding risk associated with these procedures is as follows below.

\section{Stricture dilation}

In a study of 1043 dilations of benign esophageal strictures with bougie or olive dilators, no cases of significant bleeding were recorded [102]. The same authors published a series of 2750 dilations of benign esophageal strictures using Savary bougies and again no major bleeding was recorded [103]. In a study of 472 esophageal balloon dilations, no bleeding was reported [104]. In a series of 98 balloon dilations of anastomotic strictures of the cervical esophagus no bleeding complications occurred [105]. However, none of these studies was primarily designed to evaluate the risk of bleeding associated with dilation. A study of the complications arising from 504 esophageal dilations in 237 patients with achalasia revealed $4(1.7 \%)$ asymptomatic hematomas, but no clinical bleeding [106]. In addition, there were 7 (3\%) perforations.

Regarding colonic or small bowel dilations, no cases of bleeding were reported in 7 case series of ileal or colonic dilation [107113] of strictures caused by Crohn's disease and surgical anastomoses. Two additional case series reported a small number of bleeding complications associated with dilation of ileal $(1 / 20$, $5 \%)$ and colonic strictures (1/38, 2.6\%) [114,115]. Another study reported no bleeding complications after dilation of 68-malignant and 26 benign anastomotic strictures [116]. Again, none of the above studies was primarily designed to evaluate the risk of bleeding associated with stricture dilation.

\section{Stent insertion}

No studies have specifically evaluated the bleeding risk associated with endoscopic stent placement in the esophagus, duodenum or colon in patients taking APA.

In the preparation of this Guideline a literature search on self-expandable metal colonic stent placement was restricted to studies published after 1995. In a review published in 2002 which included 58 reports of colonic stent placement published from 1990 to 2000 , consisting of case reports $(n=38)$, single case reports $(n=11)$, and reviews of the literature or letters $(n=9)$, a total of 27 bleeding complications were reported in 598 patients [117]. Of these, 24 episodes were mild and self-limited. Only 3 patients $(0.5 \%)$ suffered from severe bleeding requiring blood transfusions. A second systematic review of the literature published in 2006 collated 27 studies published between 2000 and 2006 and included 325 patients with malignant colonic obstruction [118]. There were no reported cases of gastrointestinal bleeding. A third 
systematic review of the literature selected 54 publications, none of which was randomized [119]. These were mainly case studies, editorials and literature reviews, involving in total 1192 patients (791 palliative and 401 preoperative). No cases of gastrointestinal bleeding were recorded. In a retrospective study of 102 stent placements no bleeding occurred, but there were 4 (4\%) perforations [120]. A multicenter prospective study of 44 stent placements revealed one case of hematoma that resolved spontaneously and no perforations [121].

In a systematic review of the literature of stents placed in the duodenum for malignant obstruction, 32 case series, including 10 prospective studies were identified [122]. Among 606 patients treated, 3 bleeding episodes $(0.5 \%)$ were reported. In a national survey published in 1997 there was a bleeding complication rate of $0.5 \%(2 / 434)$ with self-expandable esophageal stents [123]. An international multicenter prospective cohort study conducted between 1996 and 2003 assessed the efficacy and safety of enteral stents [124]. A total of 188 enteral stents were placed in 176 patients ( 88 pancreas cancers, 20 stomach cancers, 15 cholangiocarcinomas, 33 metastases, 8 ampullary adenocarcinoma, and 16 miscellaneous). Two patients (1\%) developed gastrointestinal bleeding; no information was given on the severity and management of bleeding.

American guidelines on the management of APA for patients undergoing endoscopic procedures classified the insertion of gastrointestinal stents as procedures with low hemorrhagic risk, in the same category as colonoscopy or EGD +/- biopsy [20]. The authors of these guidelines suggested that it is possible to insert gastrointestinal stents in patients taking aspirin and other APA.

\subsection{Percutaneous endoscopic gastrostomy (PEG) placement}

There are limited data on the bleeding risk associated with percutaneous endoscopic gastrostomy (PEG) placement in patients taking APA: three recent studies have shown that aspirin does not increase the bleeding risk (Evidence level 2+). We recommend continuing aspirin in patients undergoing PEG placement (Recommendation grade C). In the absence of appropriate studies, no recommendation can be made for patients taking clopidogrel or a combination of aspirin and thienopyridines.

Three case-control studies have specifically evaluated the risk of PEG placement in patients taking APA. A retrospective study examined 450 patients in three groups: a control group taking no APA or anticoagulants $(n=50)$, a group of patients treated with prophylactic doses of low-molecular-weight heparin $(n=152)$, and a group of patients receiving therapeutic doses of heparin, aspirin, clopidogrel, or a combination of these drugs $(n=248)$ [125]. There was no statistically significant increase in bleeding complications in patients treated with therapeutic doses of APA compared with the other groups. A second case-control study compared the risk of bleeding in patients who had continued aspirin $(n=106)$ and in those who stopped aspirin $(n=202)$ at least 7 days before PEG insertion. There was no statistically significant difference in the risk of bleeding between the two groups [126]. A recent retrospective single-center cohort case-control study of 990 patients, including 63 patients on aspirin and 50 patients on clopidogrel did not reveal any increase in bleeding in patients taking aspirin or clopidogrel [127].

\subsection{Device-assisted enteroscopy}

The bleeding risk of device-assisted enteroscopy (using either single- or double-balloon or spiral techniques) in patients taking APA has not been formally evaluated. We recommend continuing aspirin and considering discontinuation of thienopyridines (Evidence grade $D$ ).

During the last 10 years, improvements in enteroscopic techniques have rendered push enteroscopy obsolete except for evaluation and treatment of the proximal jejunum. A systematic review of the literature regarding device-assisted enteroscopy using double- or single-balloon techniques and spiral enteroscopy failed to reveal any studies which assessed the risk of bleeding in patients taking APA. The overall bleeding risk of enteroscopy has been estimated at $0.2 \%$ [128]. In a study of enteroscopy and polypectomy, bleeding occurred in $3.3 \%$ of patients [129]. Spiral enteroscopy is a newer technique that may cause mucosal trauma but has not been associated with a specific risk of bleeding [130].

\subsection{Esophageal variceal ligation (EVL)}

In the only published small-sized study of prophylactic EVL, the risk of bleeding was similar in patients taking aspirin or not (Evidence level 2-). It is recommended that for EVL aspirin is continued (Recommendation grade C) and thienopyridines are withheld (Recommendation grade $D$ ).

The risk of delayed bleeding following EVL (2.4\%-5.7\%) and sclerotherapy $(4 \%-25 \%)$ is high $[131,132]$. Five RCTs show that the risk of delayed bleeding is lower with band ligation than sclerotherapy [133 - 137]. One recent case-control study examined the risk of bleeding following EVL in a subgroup of patients taking aspirin [138]. Of 605 cirrhotic patients undergoing 837 endoscopies for emergent or prophylactic EVL, only 8 were taking aspirin. Multivariate analysis found no increased risk of bleeding with aspirin therapy.

\subsection{Hemostatic treatment using argon plasma coagulation (APC)}

There are limited data on the use of argon plasma coagulation $(A P C)$ in patients taking aspirin and other APA. In one study, aspirin and clopidogrel were not identified as risk factors for delayed bleeding after APC of mucosal vascular lesions (Evidence level 2+). It is recommended that aspirin or clopidogrel is continued in patients undergoing APC of potentially bleeding lesions (Recommendation grade C). In the absence of appropriate studies, no recommendation can be made for patients taking a combination of aspirin and thienopyridines.

APC is often used to treat vascular lesions of the gastrointestinal mucosa such as angioectasia, gastric antral vascular ectasia (GAVE or watermelon stomach)and radiation proctitis [139]. In a retrospective case-control study of APC for hemorrhagic intestinal lesions, 23 of 100 patients were on APA [140]. Although APA therapy was continued in all patients, there were no immediate complications or cases of delayed bleeding or severe anemia.

\section{Competing interests: None}

\footnotetext{
Institutions

Department of Digestive Endoscopy, Hôpital Saint Joseph, Marseille, France

Endoscopy and Bowel Cancer Screening, New Cross Hospital, Wolverhampton, UK

3 Department of Gastroenterology and Endoscopy, Hôpital universitaire l'Archet, Nice, France

4 Service de Pathologie Digestive, Hôpital Saint Philibert, Lomme, France

Cliniques Universitaires Saint-Luc, Bruxelles, Belgium

Department of Gastroenterology and Endoscopy, Hôpital de la Timone, Marseille, France
} 
Department of Digestive Endoscopy, Hôpital Ambroise Paré, Paris, France

${ }^{8}$ Division of Gastroenterology, University of Kentucky Medical Center, Lexington, Kentucky, USA

${ }^{9}$ Department of Gastroenterology, Hôpital de Montélimar, Montélimar, France

10 Department of Endoscopy, Hôpital Jean Mermoz, Lyon, France

11 Department of Gastroenterology, The General Infirmary at Leeds, Leeds, UK

12 Département d'Hématologie, AP-HP, Hôpital Bichat, INSERM, U698; Université Paris 7 Denis Diderot, Paris, France

13 Institut de Cardiologie - INSERM U 937, Groupe Hospitalier Pitié-Salpêtrière, Paris, France

14 Division of Gastroenterology and Hepatology, Mayo Clinic, Rochester, Minnesota, USA

15 Service of Gastroenterology and Hepatology, Geneva University Hospitals, Geneva, Switzerland

\section{References}

1 van Werkum JW, Heestermans AA, Zomer AC et al. Predictors of coronary stent thrombosis: the Dutch Stent Thrombosis Registry. J Am Coll Cardiol 2009; 53: 1399-1409

2 Kolh P, Wijns W, Danchin N et al. Guidelines on myocardial revascularization: The Task Force on Myocardial Revascularization of the European Society of Cardiology (ESC) and the European Association for Cardio-Thoracic Surgery (EACTS). Eur Heart J 2010; 31: 2501 - 2555

3 Montalescot G, Hulot J-S, Collet J-P. Stent thrombosis: who's guilty? Eur Heart J 2009; 30: 2685 - 2688

4 Dumonceau J, Riphaus A, Aparicio J et al. European Society of Gastrointestinal Endoscopy, European Society of Gastroenterology and Endoscopy Nurses and Associates, and the European Society of Anaesthesiology Guideline: Non-anaesthesiologist administration of propofol for GI endoscopy. Eur JAnaesthesiol 2010; 27: 1016-1030

5 Harbour $R$, Miller J. A new system for grading recommendations in evidence based guidelines. BMJ 2001; 323: 334-336

6 Fleisher LA, Beckman JA, Brown KA et al. ACC/AHA 2007 Guidelines on perioperative cardiovascular evaluation and care for noncardiac surgery: executive summary. A report of the American College of Cardiology/American Heart Association Task Force on Practice Guidelines (writing committee to revise the 2002 guidelines on perioperative cardiovascular evaluation for noncardiac surgery) developed in collaboration with the American Society of Echocardiography, American Society of Nuclear Cardiology, Heart Rhythm Society, Society of Cardiovascular Anesthesiologists, Society for Cardiovascular Angiography and Interventions, Society for Vascular Medicine and Biology, and Society for Vascular Surgery. J Am Coll Cardiol 2007; 50: 1707 1732

7 Bhatt DL, Scheiman J, Abraham NS et al. ACCF/ACG/AHA 2008 expert consensus document on reducing the gastrointestinal risks of antiplatelet therapy and NSAID use: a report of the American College of Cardiology Foundation Task Force on Clinical Expert Consensus Documents. Circulation 2008; 118: 1894-1909

8 Wiviott SD, Braunwald E, McCabe $\mathrm{CH}$ et al. Prasugrel versus clopidogrel in patients with acute coronary syndromes. N Engl J Med 2007; 357: 2001 - 2015

9 Coccheri S. Antiplatelet drugs - do we need new options? With a reappraisal of direct thromboxane inhibitors. Drugs 2010; 70: 887 908

10 Macrae FA, Tan KG, Williams CB. Towards safer colonoscopy: a report on the complications of 5000 diagnostic or therapeutic colonoscopies. Gut 1983; 24 : $376-383$

11 Rogers BH, Silvis SE, Nebel OT et al. Complications of flexible fiberoptic colonoscopy and polypectomy. Gastrointest Endosc 1975; 22: $73-77$

12 Vu CK, Korman MG, Bejer I, Davis S. Gastrointestinal bleeding after cold biopsy. Am J Gastroenterol 1998; 93: 1141 - 1143

13 Wexner SD, Garbus JE, Singh JJ SAGES Colonoscopy Study Outcomes Group. A prospective analysis of 13,580 colonoscopies. Reevaluation of credentialing guidelines. Surg Endosc 2001; 15: 251 - 261

14 Dumortier J, Napoleon B, Hedelius F et al. Unsedated transnasal EGD in daily practice: results with 1100 consecutive patients. Gastrointest Endosc 2003; 57: $198-204$

15 Maffei M, Dumortier J, Dumonceau J-M. Self-training in unsedated transnasal EGD by endoscopists competent in standard peroral EGD: prospective assessment of the learning curve. Gastrointest Endosc 2008; 67: $410-418$
16 Basson MD, Panzini L, Palmer RH. Effect of nabumetone and aspirin on colonic mucosal bleeding time. Aliment Pharmacol Ther 2001; 15: $539-542$

17 O'Laughlin JC, Hoftiezer JW, Mahoney JP, Ivey KJ. Does aspirin prolong bleeding from gastric biopsies in man? Gastrointest Endosc 1981; 27: $1-5$

18 Whitson MJ, Dikman AE, von Althann C et al. Is gastroduodenal biopsy safe in patients receiving aspirin and clopidogrel?: a prospective, randomized study involving 630 biopsies. J Clin Gastroenterol 2010 [In press]

19 Yao MD, von Rosenvinge EC, Groden C, Mannon PJ. Multiple endoscopic biopsies in research subjects: safety results from a National Institutes of Health series. Gastrointest Endosc 2009; 69: 906 - 910

20 Anderson MA, Ben-Menachem T, Gan SI et al. Management of antithrombotic agents for endoscopic procedures. Gastrointest Endosc 2009; 70: 1060 - 1070

21 Veitch AM, Baglin TP, Gershlick AH et al. Guidelines for the management of anticoagulant and antiplatelet therapy in patients undergoing endoscopic procedures. Gut 2008; 57: 1322 - 1329

22 Heldwein W, Dollhopf M, Rösch T et al. The Munich Polypectomy Study (MUPS): prospective analysis of complications and risk factors in 4000 colonic snare polypectomies. Endoscopy 2005; 37: 1116-1122

23 Sawhney MS, Salfiti N, Nelson DB et al. Risk factors for severe delayed postpolypectomy bleeding. Endoscopy 2008; 40: 115-119

$24 \mathrm{Kim}$ HS, Kim TI, Kim WH et al. Risk factors for immediate postpolypectomy bleeding of the colon: a multicenter study. Am J Gastroenterol 2006; 101: 1333-1341

25 Watabe H, Yamaji Y, Okamoto M et al. Risk assessment for delayed hemorrhagic complication of colonic polypectomy: polyp-related factors and patient-related factors. Gastrointest Endosc 2006; 64: 73 78

26 Rabeneck L, Paszat LF, Hilsden RJ et al. Bleeding and perforation after outpatient colonoscopy and their risk factors in usual clinical practice. Gastroenterology 2008; 135: 1899 - 1906 1906.e1891

27 Consolo P, Luigiano C, Strangio G et al. Efficacy, risk factors and complications of endoscopic polypectomy: ten year experience at a single center. World J Gastroenterol 2008; 14: 2364-2369

28 Dobrowolski S, Dobosz M, Babicki A et al. Prophylactic submucosal saline-adrenaline injection in colonoscopic polypectomy: prospective randomized study. Surg Endosc 2004; 18: 990 - 993

29 Lee S-H, Chung I-K, Kim S-J et al. Comparison of postpolypectomy bleeding between epinephrine and saline submucosal injection for large colon polyps by conventional polypectomy: a prospective randomized, multicenter study. World J Gastroenterol 2007; 13: 2973 2977

30 Iishi $H$, Tatsuta $M$, Narahara $H$ et al. Endoscopic resection of large pedunculated colorectal polyps using a detachable snare. Gastrointest Endosc 1996; 44: 594-597

31 Di Giorgio P, De Luca L, Calcagno G et al. Detachable snare versus epinephrine injection in the prevention of postpolypectomy bleeding: a randomized and controlled study. Endoscopy 2004; 36: 860 863

32 Kouklakis G, Mpoumponaris A, Gatopoulou A et al. Endoscopic resection of large pedunculated colonic polyps and risk of postpolypectomy bleeding with adrenaline injection versus endoloop and hemoclip: a prospective, randomized study. Surg Endosc 2009; 23: 2732 2737

33 Paspatis GA, Paraskeva K, Theodoropoulou A et al. A prospective, randomized comparison of adrenaline injection in combination with detachable snare versus adrenaline injection alone in the prevention of postpolypectomy bleeding in large colonic polyps. Am J Gastroenterol 2006; 101: $2805-2809$

34 Lee CK, Lee S-H, Park J-Y et al. Prophylactic argon plasma coagulation ablation does not decrease delayed postpolypectomy bleeding. Gastrointest Endosc 2009; 70: 353 - 361

35 Swan MP, Bourke MJ, Alexander $S$ et al. Large refractory colonic polyps: is it time to change our practice? A prospective study of the clinical and economic impact of a tertiary referral colonic mucosal resection and polypectomy service (with videos). Gastrointest Endosc 2009; 70: 1128 - 1136

36 Rey JF, Beilenhoff U, Neumann CS, Dumonceau JM. European Society of Gastrointestinal Endoscopy (ESGE) guideline: the use of electrosurgical units. Endoscopy 2010; 42: $764-772$ 
37 Van Gossum A, Cozzoli A, Adler M et al. Colonoscopic snare polypectomy: analysis of 1485 resections comparing two types of current. Gastrointest Endosc 1992; 38: $472-475$

38 Shiffman ML, Farrel MT, Yee YS. Risk of bleeding after endoscopic biopsy or polypectomy in patients taking aspirin or other NSAIDS. Gastrointest Endosc 1994; 40: 458-462

39 Yousfi M, Gostout CJ, Baron TH et al. Postpolypectomy lower gastrointestinal bleeding: potential role of aspirin. Am J Gastroenterol 2004; 99: $1785-1789$

40 Hui A, Wong R, Ching J et al. Risk of colonoscopic polypectomy bleeding with anticoagulants and antiplatelet agents: analysis of 1657 cases. Gastrointest Endosc 2004; 59: 44-48

41 Singh M, Mehta N, Murthy UK et al. Postpolypectomy bleeding in patients undergoing colonoscopy on uninterrupted clopidogrel therapy. Gastrointest Endosc 2010; 71: 998 - 1005

42 Friedland S, Leung C, Soetikno RM. Colonoscopy with polypectomy in patients taking clopidogrel. Gastroenterol Res 2009; 2: 209-212

43 Luigiano C, Ferrara F, Ghersi $S$ et al. Endoclip-assisted resection of large pedunculated colorectal polyps: technical aspects and outcome. Dig Dis Sci 2010; 55: 1726-1731

44 Shioji K, Suzuki Y, Kobayashi M et al. Prophylactic clip application does not decrease delayed bleeding after colonoscopic polypectomy. Gastrointest Endosc 2003; 57: 691 - 694

45 Friedland S, Sedehi D, Soetikno R. Colonoscopic polypectomy in anticoagulated patients. World J Gastroenterol 2009; 15: 1973 - 1976

46 Soetikno R, Kaltenbach T, Yeh R, Gotoda T. Endoscopic mucosal resection for early cancers of the upper gastrointestinal tract. J Clin Oncol 2005; $23: 4490-4498$

47 Heresbach D, Kornhauser R, Seyrig JA et al. A national survey of endoscopic mucosal resection for superficial gastrointestinal neoplasia. Endoscopy 2010; 42: 806-813

48 Pech 0 , Behrens A, May A et al. Long-term results and risk factor analysis for recurrence after curative endoscopic therapy in 349 patients with high-grade intraepithelial neoplasia and mucosal adenocarcinoma in Barrett's oesophagus. Gut 2008; 57: 1200-1206

49 Kim H-K, Chung WC, Lee B-I, Cho Y-S. Efficacy and long-term outcome of endoscopic treatment of sporadic nonampullary duodenal adenoma. Gut Liver 2010; 4: 373 - 377

50 Abbass R, Rigaux J, Al-Kawas FH. Nonampullary duodenal polyps: characteristics and endoscopic management. Gastrointest Endosc 2010; 71: 754-759

51 Alexander S, Bourke MJ, Williams SJ et al. EMR of large, sessile, sporadic nonampullary duodenal adenomas: technical aspects and longterm outcome (with videos). Gastrointest Endosc 2009; 69: 66-73

52 Lépilliez V, Chemaly M, Ponchon T et al. Endoscopic resection of sporadic duodenal adenomas: an efficient technique with a substantial risk of delayed bleeding. Endoscopy 2008; 40: 806-810

53 Apel D, Jakobs R, Spiethoff A, Riemann JF. Follow-up after endoscopic snare resection of duodenal adenomas. Endoscopy 2005; 37: $444-$ 448

54 Yamao T, Isomoto $H$, Kohno $S$ et al. Endoscopic snare papillectomy with biliary and pancreatic stent placement for tumors of the major duodenal papilla. Surg Endosc 2010; 24: 119-124

55 Irani S, Arai A, Ayub K et al. Papillectomy for ampullary neoplasm: results of a single referral center over a 10-year period. Gastrointest Endosc 2009; 70: 923 - 932

56 Katsinelos P, Paroutoglou G, Kountouras J et al. Safety and long-term follow-up of endoscopic snare excision of ampullary adenomas. Surg Endosc 2006; 20: 608-613

57 Cheng C-L, Sherman S, Fogel EL et al. Endoscopic snare papillectomy for tumors of the duodenal papillae. Gastrointest Endosc 2004; 60: $757-764$

58 Norton ID, Gostout CJ, Baron TH et al. Safety and outcome of endoscopic snare excision of the major duodenal papilla. Gastrointest Endosc 2002; 56: 239-243

59 Cao Y, Liao C, Tan A et al. Meta-analysis of endoscopic submucosal dissection versus endoscopic mucosal resection for tumors of the gastrointestinal tract. Endoscopy 2009; 41: 751 - 757

60 Takizawa K, Oda I, Gotoda T et al. Routine coagulation of visible vessels may prevent delayed bleeding after endoscopic submucosal dissection - an analysis of risk factors. Endoscopy 2008; 40: 179-183

61 Tsuji Y, Ohata K, Ito T et al. Risk factors for bleeding after endoscopic submucosal dissection for gastric lesions. World J Gastroenterol 2010; 16: 2913-2917
62 Jang JS, Choi SR, Graham DY et al. Risk factors for immediate and delayed bleeding associated with endoscopic submucosal dissection of gastric neoplastic lesions. Scand J Gastroenterol 2009; 44: 13701376

63 Mannen K, Tsunada S, Hara M et al. Risk factors for complications of endoscopic submucosal dissection in gastric tumors: analysis of 478 lesions. J Gastroenterol 2010; 45: 30 - 36

64 Okada K, Yamamoto Y, Kasuga A et al. Risk factors for delayed bleeding after endoscopic submucosal dissection for gastric neoplasm. Surg Endosc 2010 [In press]

65 Ono S, Fujishiro M, Niimi K et al. Technical feasibility of endoscopic submucosal dissection for early gastric cancer in patients taking anti-coagulants or anti-platelet agents. Dig Liver Dis 2009; 41: 725 728

66 Freeman $M L$, Nelson DB, Sherman S et al. Complications of endoscopic biliary sphincterotomy. N Engl J Med 1996; 335: $909-918$

67 Freeman ML. Understanding risk factors and avoiding complications with endoscopic retrograde cholangiopancreatography. Curr Gastroenterol Rep 2003; 5: 145-153

68 Verma D, Kapadia A, Adler DG. Pure versus mixed electrosurgical current for endoscopic biliary sphincterotomy: a meta-analysis of adverse outcomes. Gastrointest Endosc 2007; 66: 283 - 290

69 Hussain N, Alsulaiman R, Burtin P et al. The safety of endoscopic sphincterotomy in patients receiving antiplatelet agents: a case-control study. Aliment Pharmacol Ther 2007; 25: 579-584

70 Hui C-K, Lai K-C, Yuen M-F et al. Does withholding aspirin for one week reduce the risk of post-sphincterotomy bleeding? Aliment Pharmacol Ther 2002; 16: 929-936

71 Attasaranya S, Cheon YK, Vittal $\mathrm{H}$ et al. Large-diameter biliary orifice balloon dilation to aid in endoscopic bile duct stone removal: a multicenter series. Gastrointest Endosc 2008; 67: 1046-1052

72 Ersoz G, Tekesin O, Ozutemiz AO, Gunsar F. Biliary sphincterotomy plus dilation with a large balloon for bile duct stones that are difficult to extract. Gastrointest Endosc 2003; 57: 156-159

73 Maydeo A, Bhandari S. Balloon sphincteroplasty for removing difficult bile duct stones. Endoscopy 2007; 39: 958-961

74 Minami A, Hirose S, Nomoto T, Hayakawa S. Small sphincterotomy combined with papillary dilation with large balloon permits retrieval of large stones without mechanical lithotripsy. World J Gastroenterol 2007; $13: 2179-2182$

75 Misra SP, Dwivedi M. Large-diameter balloon dilation after endoscopic sphincterotomy for removal of difficult bile duct stones. Endoscopy 2008; 40: 209-213

$76 \mathrm{Heo} \mathrm{JH,} \mathrm{Kang} \mathrm{DH,} \mathrm{Jung} \mathrm{HJ} \mathrm{et} \mathrm{al.} \mathrm{Endoscopic} \mathrm{sphincterotomy} \mathrm{plus} \mathrm{large-}$ balloon dilation versus endoscopic sphincterotomy for removal of bile-duct stones. Gastrointest Endosc 2007; 66: 720-726; quiz 768, 771

77 Baron TH, Harewood GC. Endoscopic balloon dilation of the biliary sphincter compared to endoscopic biliary sphincterotomy for removal of common bile duct stones during ERCP: a metaanalysis of randomized, controlled trials. Am J Gastroenterol 2004; 99: 1455 - 1460

78 Weinberg BM, Shindy W, Lo S. Endoscopic balloon sphincter dilation (sphincteroplasty) versus sphincterotomy for common bile duct stones. Cochrane Database Syst Rev 2006 CD004890

79 Disario JA, Freeman ML, Bjorkman DJ et al. Endoscopic balloon dilation compared with sphincterotomy for extraction of bile duct stones. Gastroenterology 2004; 127: 1291 - 1299

80 Dumonceau J-M, Andriulli A, Deviere J et al. European Society of Gastrointestinal Endoscopy (ESGE) Guideline: prophylaxis of post-ERCP pancreatitis. Endoscopy 2010; 42: 503 - 515

81 Dumonceau J-M, Rigaux J, Kahaleh $M$ et al. Prophylaxis of post-ERCP pancreatitis: a practice survey. Gastrointest Endosc 2010; 71: $934-$ 939

82 Artifon ELA, Sakai P, Ishioka S et al. Endoscopic sphincterotomy before deployment of covered metal stent is associated with greater complication rate: a prospective randomized control trial. J Clin Gastroenterol 2008; 42: 815-819

83 Hui C-K, Lai K-C, Yuen M-F et al. Does the addition of endoscopic sphincterotomy to stent insertion improve drainage of the bile duct in acute suppurative cholangitis? Gastrointest Endosc 2003; 58: $500-504$

84 Bergman JJ, Rauws EA, Tijssen JG et al. Biliary endoprostheses in elderly patients with endoscopically irretrievable common bile duct stones: report on 117 patients. Gastrointest Endosc 1995; 42: 195 201 
85 Chan AC, $\mathrm{Ng}$ EK, Chung SC et al. Common bile duct stones become smaller after endoscopic biliary stenting. Endoscopy 1998; 30: $356-$ 359

86 Han J, Moon JH, Koo HC et al. Effect of biliary stenting combined with ursodeoxycholic acid and terpene treatment on retained common bile duct stones in elderly patients: a multicenter study. Am J Gastroenterol 2009; 104: 2418-2421

87 Horiuchi A, Nakayama Y, Kajiyama $M$ et al. Biliary stenting in the management of large or multiple common bile duct stones. Gastrointest Endosc 2010; 71: 1200 - 1203.e1202

88 Pisello F, Geraci G, Li Volsi F et al. Permanent stenting in "unextractable" common bile duct stones in high risk patients. A prospective randomized study comparing two different stents. Langenbecks Arch Surg 2008; 393: 857 -863

89 Al-Haddad M, Wallace MB, Woodward TA et al. The safety of fine-needle aspiration guided by endoscopic ultrasound: a prospective study. Endoscopy 2008; 40: 204- 208

90 Bentz JS, Kochman ML, Faigel DO et al. Endoscopic ultrasound-guided real-time fine-needle aspiration: clinicopathologic features of 60 patients. Diagn Cytopathol 1998; 18: 98-109

91 Mortensen MB, Fristrup C, Holm FS et al. Prospective evaluation of patient tolerability, satisfaction with patient information, and complications in endoscopic ultrasonography. Endoscopy 2005; 37: 146 153

92 Williams DB, Sahai AV, Aabakken L et al. Endoscopic ultrasound guided fine needle aspiration biopsy: a large single centre experience. Gut 1999; 44: 720 - 726

93 Bournet B, Migueres I, Delacroix M et al. Early morbidity of endoscopic ultrasound: 13 years' experience at a referral center. Endoscopy 2006; 38: 349 - 354

94 Wiersema MJ, Vilmann P, Giovannini M et al. Endosonography-guided fine-needle aspiration biopsy: diagnostic accuracy and complication assessment. Gastroenterology 1997; 112: 1087-1095

95 Kien-Fong Vu C, Chang F, Doig L, Meenan J. A prospective control study of the safety and cellular yield of EUS-guided FNA or Trucut biopsy in patients taking aspirin, nonsteroidal anti-inflammatory drugs, or prophylactic low molecular weight heparin. Gastrointest Endosc 2006; 63: 808-813

96 Varadarajulu S, Eloubeidi MA. Frequency and significance of acute intracystic hemorrhage during EUS-FNA of cystic lesions of the pancreas. Gastrointest Endosc 2004; 60: 631 - 635

97 Brugge WR, Lewandrowski K, Lee-Lewandrowski E et al. Diagnosis of pancreatic cystic neoplasms: a report of the cooperative pancreatic cyst study. Gastroenterology 2004; 126: 1330 - 1336

98 Al-Haddad M, Gill KR, Raimondo $M$ et al. Safety and efficacy of cytology brushings versus standard fine-needle aspiration in evaluating cystic pancreatic lesions: a controlled study. Endoscopy 2010; 42: $127-132$

99 Bruno M, Bosco M, Carucci P et al. Preliminary experience with a new cytology brush in EUS-guided FNA. Gastrointest Endosc 2009; 70: $1220-1224$

100 Sendino O, Fernández-Esparrach G, Solé M et al. Endoscopic ultrasonography-guided brushing increases cellular diagnosis of pancreatic cysts: A prospective study. Dig Liver Dis 2010 [In press]

101 Thomas T, Bebb J, Mannath J et al. EUS-guided pancreatic cyst brushing: a comparative study in a tertiary referral centre. JOP 2010; 11 : $163-169$

102 Pereira-Lima JC, Ramires RP, Zamin I et al. Endoscopic dilation of benign esophageal strictures: report on 1043 procedures. Am J Gastroenterol 1999; 94: 1497-1501

103 Raymondi R, Pereira-Lima JC, Valves A et al. Endoscopic dilation of benign esophageal strictures without fluoroscopy: experience of 2750 procedures. Hepatogastroenterology 2008; 55: $1342-1348$

104 Polese L, Angriman I, Bonello E et al. Endoscopic dilation of benign esophageal strictures in a surgical unit: a report on 95 cases. Surg Laparosc Endosc Percutan Tech 2007; 17: 477 - 481

105 Williams VA, Watson TJ, Zhovtis S et al. Endoscopic and symptomatic assessment of anastomotic strictures following esophagectomy and cervical esophagogastrostomy. Surg Endosc 2008; 22: 1470-1476

106 Metman EH, Lagasse JP, d'Alteroche L et al. Risk factors for immediate complications after progressive pneumatic dilation for achalasia. Am J Gastroenterol 1999; 94: 1179-1185

107 Araujo SEA, Costa AF. Efficacy and safety of endoscopic balloon dilation of benign anastomotic strictures after oncologic anterior rectal resection: report on 24 cases. Surg Laparosc Endosc Percutan Tech 2008; 18: 565 - 568

108 Ajlouni Y, Iser JH, Gibson PR. Endoscopic balloon dilatation of intestinal strictures in Crohn's disease: safe alternative to surgery. J Gastroenterol Hepatol 2007; 22: 486-490

109 Thomas-Gibson S, Brooker JC, Hayward CMM et al. Colonoscopic balloon dilation of Crohn's strictures: a review of long-term outcomes. Eur J Gastroenterol Hepatol 2003; 15: 485 - 488

110 Dear KL, Hunter JO. Colonoscopic hydrostatic balloon dilatation of Crohn's strictures. J Clin Gastroenterol 2001; 33: 315 - 318

111 Couckuyt H, Gevers AM, Coremans G et al. Efficacy and safety of hydrostatic balloon dilatation of ileocolonic Crohn's strictures: a prospective longterm analysis. Gut 1995; 36: 577 - 580

112 Breysem Y, Janssens JF, Coremans G et al. Endoscopic balloon dilation of colonic and ileo-colonic Crohn's strictures: long-term results. Gastrointest Endosc 1992; 38: 142 - 147

113 Blomberg B, Rolny P, Järnerot G. Endoscopic treatment of anastomotic strictures in Crohn's disease. Endoscopy 1991; 23: 195-198

114 Nomura E, Takagi S, Kikuchi T et al. Efficacy and safety of endoscopic balloon dilation for Crohn's strictures. Dis Colon Rectum 2006; 49: $59-67$

115 Sabaté J-M, Villarejo J, Bouhnik Y et al. Hydrostatic balloon dilatation of Crohn's strictures. Aliment Pharmacol Ther 2003; 18: 409-413

116 Suchan KL, Muldner A, Manegold BC. Endoscopic treatment of postoperative colorectal anastomotic strictures. Surg Endosc 2003; 17: $1110-1113$

117 Khot UP, Lang AW, Murali K, Parker MC. Systematic review of the efficacy and safety of colorectal stents. Br J Surg 2002; 89: 1096-1102

118 Dionigi $G$, Villa F, Rovera $F$ et al. Colonic stenting for malignant disease: review of literature. Surg Oncol 2007; 16 (Suppl. 1): S153-155

119 Sebastian S, Johnston S, Geoghegan T et al. Pooled analysis of the efficacy and safety of self-expanding metal stenting in malignant colorectal obstruction. Am J Gastroenterol 2004; 99: 2051 - 2057

120 Athreya S, Moss J, Urquhart G et al. Colorectal stenting for colonic obstruction: the indications, complications, effectiveness and outcome - 5 year review. Eur J Radiol 2006; 60: 91 - 94

121 Repici A, Fregonese D, Costamagna $G$ et al. Ultraflex precision colonic stent placement for palliation of malignant colonic obstruction: a prospective multicenter study. Gastrointest Endosc 2007; 66: 920 927

122 Dormann A, Meisner S, Verin N, Wenk Lang A. Self-expanding metal stents for gastroduodenal malignancies: systematic review of their clinical effectiveness. Endoscopy 2004; 36: 543 - 550

123 Ramirez FC, Dennert B, Zierer ST, Sanowski RA. Esophageal self-expandable metallic stents - indications, practice, techniques, and complications: results of a national survey. Gastrointest Endosc 1997; 45: $360-364$

124 Telford JJ, Carr-Locke DL, Baron TH et al. Palliation of patients with malignant gastric outlet obstruction with the enteral Wallstent: outcomes from a multicenter study. Gastrointest Endosc 2004; 60: 916-920

125 Ruthmann O, Seitz A, Richter S et al. [Percutaneous endoscopic gastrostomy. Complications with and without anticoagulation]. Chirurg 2010; 81: 247-254

126 Coronel M, Banner K, Nannegari V et al. Does aspirin increase the risk of bleeding for percutaneous endoscopic gastrostomy procedure? Gastrointest Endosc 2006; 63: AB113

127 Richter J, Patrie J, Richter $R$ et al. Use of high-dose aspirin or clopidogrel before or after percutaneous endoscopic gastrostomy is not associated with post-procedural bleeding. Gastrointest Endosc 2010; 71: AB114

128 Gerson LB, Tokar J, Chiorean $M$ et al. Complications associated with double balloon enteroscopy at nine US centers. Clin Gastroenterol Hepatol 2009; 7: 1177-1182

129 Mensink PBF, Haringsma J, Kucharzik T et al. Complications of doubleballoon enteroscopy: a multicenter survey. Endoscopy 2007; 39: $613-615$

130 Buscaglia JM, Dunbar KB, Okolo PI et al. The spiral enteroscopy training initiative: results of a prospective study evaluating the Discovery SB overtube device during small bowel enteroscopy (with video). Endoscopy 2009; 41: 194-199

131 Piai G, Cipolletta L, Claar M et al. Prophylactic sclerotherapy of highrisk esophageal varices: results of a multicentric prospective controlled trial. Hepatology 1988; 8: 1495 - 1500 
132 Schmitz RJ, Sharma P, Badr AS et al. Incidence and management of esophageal stricture formation, ulcer bleeding, perforation, and massive hematoma formation from sclerotherapy versus band ligation. Am J Gastroenterol 2001; 96: 437-441

133 Baroncini D, Milandri GL, Borioni D et al. A prospective randomized trial of sclerotherapy versus ligation in the elective treatment of bleeding esophageal varices. Endoscopy 1997; 29: 235 - 240

134 Gimson AE, Ramage JK, Panos MZ et al. Randomised trial of variceal banding ligation versus injection sclerotherapy for bleeding oesophageal varices. Lancet 1993; 342: 391 - 394

135 Laine L, el-Newihi HM, Migikovsky B et al. Endoscopic ligation compared with sclerotherapy for the treatment of bleeding esophageal varices. Ann Intern Med 1993; 119: 1 - 7

136 Lo GH, Lai KH, Cheng JS et al. A prospective, randomized trial of sclerotherapy versus ligation in the management of bleeding esophageal varices. Hepatology 1995; 22: $466-471$

137 Stiegmann GV, Goff JS, Michaletz-Onody PA et al. Endoscopic sclerotherapy as compared with endoscopic ligation for bleeding esophageal varices. N Engl J Med 1992; 326: 1527-1532

138 Vanbiervliet G, Giudicelli-Bornard S, Piche T et al. Predictive factors of bleeding related to post-banding ulcer following endoscopic variceal ligation in cirrhotic patients: a case-control study. Aliment Pharmacol Ther 2010; 32: 225-232
139 Herrera S, Bordas JM, Llach J et al. The beneficial effects of argon plasma coagulation in the management of different types of gastric vascular ectasia lesions in patients admitted for GI hemorrhage. Gastrointest Endosc 2008; 68: 440-446

140 Kwan V, Bourke MJ, Williams SJ et al. Argon plasma coagulation in the management of symptomatic gastrointestinal vascular lesions: experience in 100 consecutive patients with long-term follow-up. Am J Gastroenterol 2006; 101: 58-63

\section{Supporting information}

The following material is available online

online content including Appendix e1 - e3 viewable at: www.thieme-connect.de/ejournals/abstract/endoscopy/ DOI 10.1016/j.dld.2010.07.009 